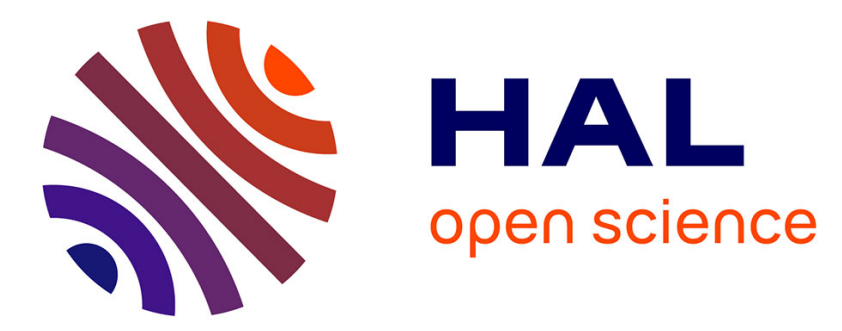

\title{
Geothermal contribution to the energy mix of a heating network when using Aquifer Thermal Energy Storage: modeling and application to the Paris basin
}

Arnaud Réveillère, Virginie Hamm, Hervé Lesueur, Elisabeth Cordier, Patrick Goblet

\section{To cite this version:}

Arnaud Réveillère, Virginie Hamm, Hervé Lesueur, Elisabeth Cordier, Patrick Goblet. Geothermal contribution to the energy mix of a heating network when using Aquifer Thermal Energy Storage: modeling and application to the Paris basin. Geothermics, 2013, 47, pp.69-79. 10.1016/j.geothermics.2013.02.005 . hal-00814929

\author{
HAL Id: hal-00814929 \\ https://hal.science/hal-00814929
}

Submitted on 18 Apr 2013

HAL is a multi-disciplinary open access archive for the deposit and dissemination of scientific research documents, whether they are published or not. The documents may come from teaching and research institutions in France or abroad, or from public or private research centers.
L'archive ouverte pluridisciplinaire HAL, est destinée au dépôt et à la diffusion de documents scientifiques de niveau recherche, publiés ou non, émanant des établissements d'enseignement et de recherche français ou étrangers, des laboratoires publics ou privés. 


\title{
Geothermal contribution to the energy mix of a heating network when using Aquifer Thermal Energy Storage: modeling and application to the Paris basin
}

\author{
A. Réveillère ${ }^{1}$, V. Hamm ${ }^{1}$, H. Lesueur ${ }^{1}$, E. Cordier ${ }^{2}$, P. Goblet ${ }^{2}$ \\ ${ }^{1}$ : BRGM, 3 av. Claude Guillemin, 45000 Orleans, France \\ 2: Mines ParisTech, 35 rue Saint Honoré, 77305 Fontainebleau, France \\ Corresponding author e-mail address: arnaud.reveillere@centraliens.net
}

\begin{abstract}
Aquifer Thermal Energy Storage (ATES) is a promising solution for reducing the time mismatch between energy production and demand in urban environments, and recent successful experiences suggest that technical issues can be overcome. The Paris area is $a$ priori a favorable region, since there is locally a surplus of heat production during the summer, an appropriate geological reservoir and both existing and projected district heating networks. This article focuses on a remaining issue: estimating the geothermal contribution to the energy mix of a district heating network over time when using an ATES. This result would then enable estimating the fuel cost savings obtained by avoiding the consumption of expensive energies during the winter retrieval. This work considers an ATES made of two reversible wells reaching the Dogger aquifer and providing energy to a new low-temperature district heating network heating 7,500 housing-equivalents. Non-geothermal energy sources with fluctuating prices over time are used for winter peak demand and for summer heat storage. The temperature of brine unloading at the hot and cold wells is simulated and the adequacy of this geothermal system to meet the load is studied in order to evaluate the time dependent energy mix of the network. Results suggest that in average over the 30 years of operation, the ATES delivers $54 \mathrm{GWh}$ per year to the heating system, i.e. a power of $9.5 \mathrm{MW}$ during the 34 unloading winter weeks. The geothermal energy share in the energy mix is $70 \%$, higher than the $50 \%$ possible with a conventional geothermal doublet. The ratio of energy delivered by the ATES divided by energy spent for storage reaches $143 \%$, and is only slightly reduced to $137 \%$ when the cold storage is located on an existing cold plume created by past geothermal energy operations.
\end{abstract}

\section{Introduction}

1.1. The ATES concept and advantages of seasonal energy storage In 2008, the residential and tertiary sectors were the largest contributors to total energy consumption in France ( $43 \%$ of a total of $160 \mathrm{Mtoe}$ ) and were responsible for $23 \%$ of the national $\mathrm{CO}_{2}$ emissions, according to Ademe, the French Energy Agency (Ademe, 2009). These are therefore priority sectors for the attainment of national objectives to reduce energy consumption and promote renewable energies. France is committed to reducing its national greenhouse gas emissions by a factor of 4 and to increasing the heat produced from renewable energies by $50 \%$ before 2050 , in relation to 1990 levels. 
In these sectors, $72 \%$ of the energy is used for space heating and household hot water supply. The heating energy demand is characterized by large fluctuations over time, with both short period variations (mornings, weekends, etc.) and variations in the weather in temperate zones imposing a highly seasonal pattern. Since most of the energy sources used to meet the seasonal peaks are of fossil origin, they make a significant contribution to $\mathrm{CO}_{2}$ emissions. Furthermore, some of the energy produced inevitably by various processes (e.g. municipal waste incineration) may not be needed during the summer and, if it is not collected, will be wasted. The seasonal storage of thermal energy overcomes this temporal mismatch between production and consumption. The economic savings in operation and environmental advantages of seasonal energy storage are therefore based on the storage of green or surplus energy when it is available in the summer and its retrieval during the winter in order to avoid using expensive fossil energies.

The geological underground has proven to be a suitable medium for storing large quantities of heat over a long period, notably because of the thermal capacity of the ground and the low thermal conductivity of rocks (Nielsen, 2003). Aquifer Thermal Energy Storage (ATES) is therefore an interesting technology for matching the demand of a district heating network with supply of heat on an inter-seasonal basis. During the summer, cold water is extracted from underground and warmed using the available surplus heat (Fig. 1, top panel); during the winter, hot water is extracted from the hot storage and used directly for district heating (Fig. 1, bottom panel). Moreover, ATES technology offers large storage capacity while requiring only limited ground space, and is therefore well suited to urban environments.

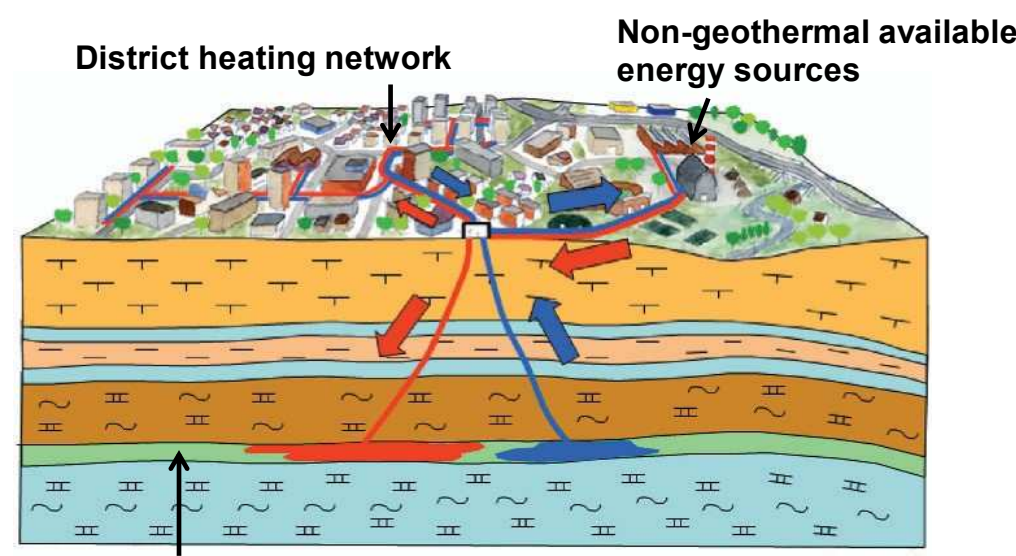

Deep saline aquifer

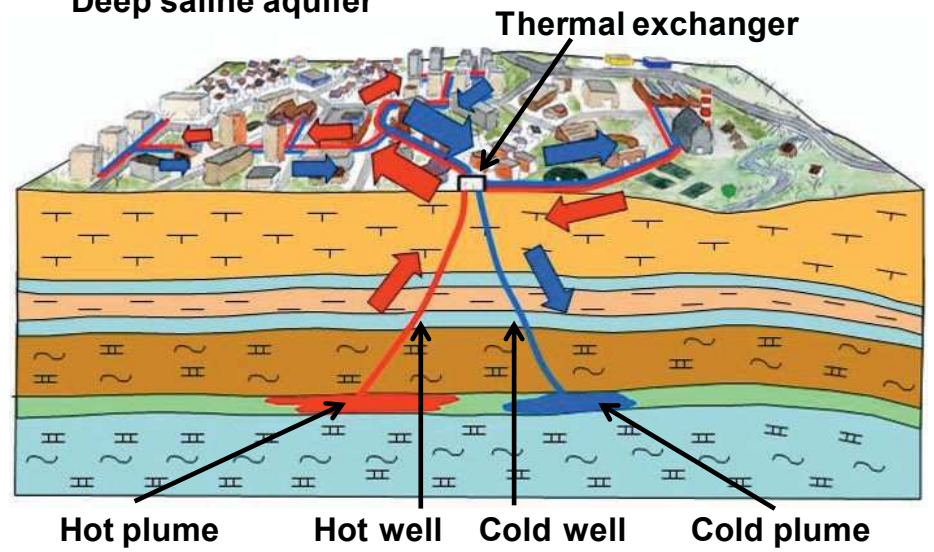

Fig. 1: Illustration of the doublet ATES concept during summer storage (top panel) and winter unloading (bottom panel). Adapted from Ungerer \& Le Bel, 2006. 


\subsection{Lessons learnt from past experience with aquifer hot storage}

According to Sanner (1999), the first reported experiment with hot water seasonal storage in aquifers was at Auburn University in the USA, in 1976. The accumulated technical and operational experience with ATES technology has been compiled and collated on the initiative of the International Energy Agency, in Annex 12 of the Energy Conservation Through Energy Storage program (IEA-ECES). For instance, nine deep ATES projects, including the one at Auburn University, are reviewed in the state of the art summary by Sanner (1999).

At least four of these twelve projects (Plaisir Thiverval-Grignon in France, Dorigny in Switzerland, Horsholm in Denmark and Utrecht in the Netherlands) have experienced operating difficulties, the most common causes being corrosion or clogging problems due to geochemical changes in the groundwater resulting from temperature and pressure variations. The Le Plaisir Thiverval-Grignon project, in France, is a typical example of failure due to adverse complex geochemical and mechanical interactions. Geothermal water, initially at a natural temperature of $25^{\circ} \mathrm{C}$, was stored under pressure at $180^{\circ} \mathrm{C}$. Poorly designed completion and insufficient filtering led to rapid and repeated blocking of the hot well (in production and injection). A handling error then totally clogged the well and the project was abandoned in 1990, after a few years of operation. The operators concluded that the "objective of storage at $180^{\circ} \mathrm{C}$ appears to be too ambitious. It led to technological decisions which jeopardized the reliability of the installation" (Sanner, 1999). Subsequent, ATES projects in France suffered the repercussions of this failure which, to date, remains the last experience with ATES.

Contrary to the setbacks observed on some hot storage projects during the eighties and nineties, recent hot storage operations are operating successfully. In Neubrendenburg, an ATES targeting a deep saline aquifer $(1200 \mathrm{~m}-1300 \mathrm{~m})$ has been operating since 2004 and unloaded 4-5 MW into the local heating network during the first winter. The Neubrendenburg plant reuses two former wells retrofitted with a composite fiber glass / epoxy liner to avoid corrosion issues (Kabus et al., 2005, 2006) and uses specific geochemical and microbiological monitoring to validate the gradual increase in storage temperature (Kabus et al., 2009). Other ATES plants are operating successfully in shallower aquifers in the Netherlands, Canada, Sweden, Germany, Belgium and some other countries, as presented by Andersson (2007) and Lee (2010).

As summarized by Bourbiaux (2011), the ATES concept did not emerge as a heat storage solution during the eighties and nineties because of the combined influence of two issues: (1) low hydrocarbon prices and (2) failures in pilot plants due to inadequate or too severe conditions. The above-mentioned more recent examples of success attest that the second issue can be overcome by adequate project design (proper operation design and material selection) and operation (water treatment) to ensure suitability to the geological and geochemical context. The economic issue remains and requires estimating the energy consumption over time. This article develops a method to calculate the energy mix of a heating network over time. 


\subsection{Opportunities for ATES development in the Paris basin}

\subsubsection{Context overview}

In addition to the resolving of technical issues, industrial deployment of ATES technology depends on the economic profitability for project developers. Three conditions must be met locally to consider seasonal heat storage: there must be (i) a surplus of heat in the summer, (ii) a geological reservoir with good hydrodynamic and thermal properties and (iii) a district heating network that is suitable for winter unloading of the heat. As demonstrated below, these conditions are present in the Paris basin, which is therefore a favorable region for future ATES operations:

i) Three incineration plants operated by the SYTCOM are feeding 300,000 toe per year into heating networks, equivalent to the consumption of 300,000 housingequivalents (SYTCOM website, 2011). This waste incineration is currently providing baseload energy to feed a large, steam heating network in the region. Average power of $100 \mathrm{MW}$ is available during the summer low-demand period.

ii) There is a considerable body of knowledge on the underlying Dogger aquifer resulting from successful experiences with low-enthalpy geothermal energy (Lopez et al., 2010). This aquifer is the focus of this study.

iii) The lle-de-France region around Paris is the French region where district heating networks are the most developed, and one where they are still developing. They supply heat to 1 million housing-equivalents, 150,000 of which are heated by geothermal energy (Via Sèva and Ademe, 2010).

However, in spite of this favorable context, these three criteria alone are not sufficient to assess the profitability of an ATES in the Paris region. Unlike conventional geothermal solutions, the temperature of the resource varies over weeks and with the seasons, as does the power available to feed a heating network. Moreover, the economic profitability of storage is also related to the strong fluctuations in fuel costs over time (summer storage of cheap surplus energy).

These two reasons make necessary the use of models that enable tracking of the temperature of the geothermal resource (ATES) and of the characteristics of the load (inlet and outlet temperatures, network flow rate) in order to estimate the geothermal feed power at a given time. It is then possible to calculate the energy mix of the network, which is considered to be composed of geothermal energy (from the ATES) and of non-geothermal available energy in time-varying proportions.

It should be noted that the name Aquifer Thermal Energy Storage (ATES) suggests that both the energy used for storage and that retrieved during unloading are considered. Since the latter results from interaction between the heating network characteristics (i.e. inlet and outlet temperatures, flow rate) and the geothermal resource (i.e. retrieved temperatures and flow rate), the acronym ATES should be seen as referring to the whole system comprising two reversible wells, the heat exchangers and the heating network. This is the definition assumed in this article. 


\subsubsection{ATES as a potential method for creating or restoring the geothermal potential of a region}

As mentioned in the previous section, the Dogger aquifer has been exploited intensively for 40 years. According to Lopez et al. (2010), there were 55 doublets in the eighties and 35 lowenergy geothermal plants are currently operating. This successful experience has left cold plumes where new low-enthalpy geothermal energy operations are no longer of interest. Moreover, the density of operations is not uniform: the wells are concentrated in four main areas while others are not used, partly because of their lower geothermal fluid temperature (Lopez et al., 2010). ATES may therefore be seen as an opportunity to use the aquifer by creating or restoring the possibility of using geothermal energy in areas where the resource is not warm enough for conventional applications, as a result of natural conditions or former geothermal exploitation (Ungerer and Le Bel, 2006). To address this impact correctly, we will consider positioning the cold well of the ATES in the aquifer at $65^{\circ} \mathrm{C}$ (reference case corresponding to the favorable regions of the Dogger aquifer) or at the location of the cold plume of a former doublet (alternative case).

This article therefore simulates seasonal heat storage in the Dogger aquifer (in Section 2). In Section 3, it presents an energy model used for combining these results with the district heating network load characteristics to assess energy consumption over time. Section 4 presents the results of this model applied to a heating network in the Paris region in terms of the network's energy mix over time.

\section{Modeling of heat storage in the Dogger aquifer}

\subsection{Model description}

\subsubsection{Reservoir characteristics}

As a result of past low geothermal energy exploitation, 124 wells reached the Dogger and 70 are still operating. The aquifer's characteristics are therefore well known thanks to production tests, flow meter logs and NPHI logs which give valuable information on aquifer porosity, intrinsic transmissivity, number and thickness of productive layers and interstrata. In order to assess the hydraulic and thermal impacts of the ATES on the Dogger aquifer, we have used reservoir properties representative of this aquifer, as summarized in Table 1. 


\begin{tabular}{ll}
\hline Reservoir depth (m/ground surface) & 1460 \\
\hline Average productive thickness $(\mathrm{m})$ & 10 \\
Average intrinsic transmissivity $(\mathrm{Dm})$ & 35 \\
Effective porosity $(\%)$ & 15 \\
Average initial pressure at reservoir depth $(\mathrm{bar})$ & 160 \\
Average Initial reservoir temperature $\left({ }^{\circ} \mathrm{C}\right)$ & 65 \\
Fluid salinity $(\mathrm{g} / \mathrm{l})$ & 19 \\
Fluid dynamic viscosity $(\mathrm{mPa} . \mathrm{s})$ at $65{ }^{\circ} \mathrm{C}$ & 0.44 \\
Longitudinal dispersivity $(\mathrm{m})$ & 20 \\
Transversal dispersivity $(\mathrm{m})$ & 10 \\
Aquifer specific heat capacity $\left(\mathrm{MJ} / \mathrm{m}^{3} /{ }^{\circ} \mathrm{C}\right)$ & 2.5 \\
Cap- and base-rock specific heat capacity $\left(\mathrm{MJ} / \mathrm{m} 3 /{ }^{\circ} \mathrm{C}\right)$ & 2.2 \\
Fluid specific heat capacity $\left(\mathrm{MJ} / \mathrm{m}^{3} /{ }^{\circ} \mathrm{C}\right)$ at $65^{\circ} \mathrm{C}$ & 4.166 \\
Aquifer thermal conductivity $\left(\mathrm{W} / \mathrm{m} /{ }^{\circ} \mathrm{C}\right)$ & 2.5 \\
Cap- and base-rock thermal conductivity $\left(\mathrm{W} / \mathrm{m} /{ }^{\circ} \mathrm{C}\right)$ & 2 \\
Fluid thermal conductivity $\left(\mathrm{W} / \mathrm{m} /{ }^{\circ} \mathrm{C}\right)$ at $65^{\circ} \mathrm{C}$ & 0.664 \\
\hline
\end{tabular}

Table 1: Reservoir characteristics

\subsubsection{Conceptual reservoir model}

The conceptual model used for hydrothermal modeling is based on a one-layer structure where the productive layers deduced from the flowmeter log are cumulated (Fig. 2). The interstrata between productive layers, which act as a thermal buffer, are not considered here. Indeed, a study of the influence of the reservoir structure (Cordier and Goblet, 2009) shows that the simulated reservoir temperatures at each reversible well obtained with a one layer model or with a multilayer model (productive layers separated by impervious interstrata) are very similar.

The model uses a horizontal plane of symmetry in the middle of the aquifer and is therefore based on a three-dimensional meshing representing the upper half reservoir and the semiinfinite cap-rock.
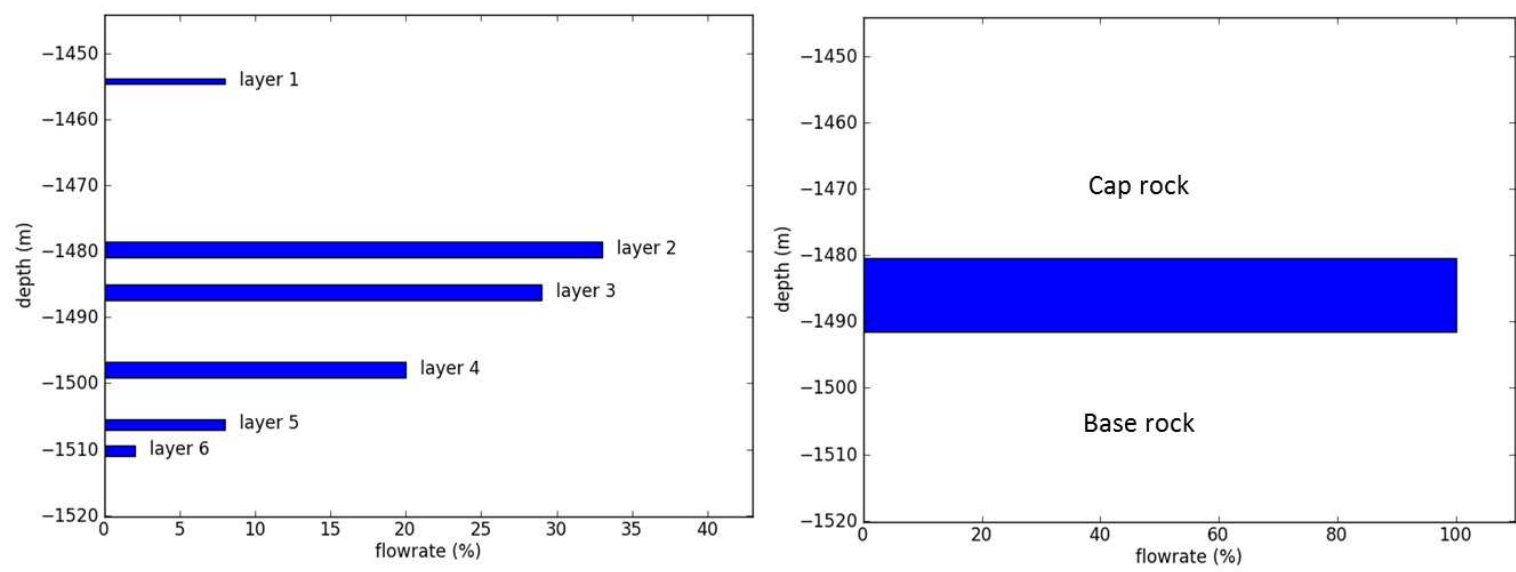

Fig. 2: Left: example of a flowmeter log (6 productive layers); right: one-layer equivalent model used for the purpose of modeling (accumulates productive layers) 


\subsubsection{Simulation tools}

The reservoir simulation results presented in this article are a small part of a much larger set (Hamm, 2011, Cordier and Goblet, 2010) intended to explore various ATES geometries. Thus, simulations were carried out using two modeling softwares: MARTHE developed at BRGM (Thierry, 1990) and METIS developed at Mines ParisTech (Cordier and Goblet, 1998).

MARTHE is based on the finite volumes method. It is designed for fluid flow and general transfer processes (heat, solute) in porous media for variable geometries. METIS is based on the finite elements method and solves the same equations as MARTHE.

\subsection{Simulation conditions and results}

\subsubsection{Simulation conditions}

Unlike a "conventional geothermal exploitation", using one producer and one injector without reversibility, this ATES system produces a hot plume in the reservoir around the hot storage well during the summer period (hot well operates as an injector and the cold well as a producer) and a cold plume around the cold storage well during the winter period (hot well operates as a producer and the cold well as an injector).

The ATES system was simulated for a total of 30 one-year cycles each consisting of:

- 14 weeks of hot water storage at a constant flow rate of $300 \mathrm{~m}^{3} / \mathrm{h}$ and $95^{\circ} \mathrm{C}$; this also induces water unloading at the cold well;

- 34 weeks of hot water unloading at varying flow rates and temperatures; the average flow rate was $242 \mathrm{~m}^{3} / \mathrm{h}$ and the average injection temperature at the "cold well" was $46.1^{\circ} \mathrm{C}$.

- 2 weeks pause at the end of each period

These baseline operating conditions is a hypothesis justified a posteriori since it maximizes the use of geothermal energy on the heating network. We note that this ATES operates with an unbalanced mass flow which results in an average annual overall flow of $80 \mathrm{~m}^{3} / \mathrm{h}$ from the hot well to the cold well.

\subsubsection{Temperature over time}

Fig. 3 presents the loading and unloading temperature at the hot and cold well for the reference case, where the aquifer is initially at a uniform temperature of $65^{\circ} \mathrm{C}$. The results from the two codes fit well, allowing confidence in the validity of the simulated temperature unloading results, despite the fact that they are based on very different discretization approaches. The average of these two results is used for the energy calculations (section 3 ). 


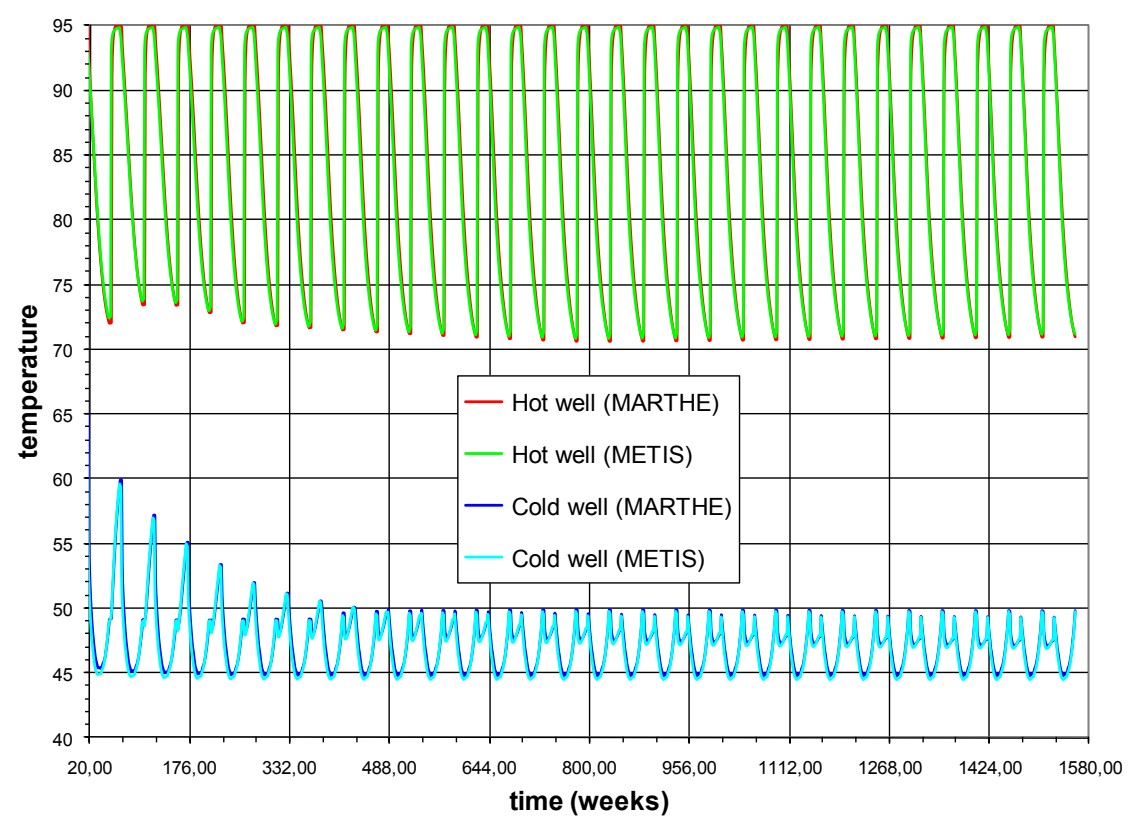

Fig. 3: Temperature curves computed at the hot and cold wells - comparison of MARTHE and METIS results

In addition, we simulate re-use of the location of a former operation, assuming that a previously existing conventional geothermal doublet has left a $430 \mathrm{~m}$ radius cold plume in the reservoir, with a minimum temperature of $45.6^{\circ} \mathrm{C}$. The ATES cold well is located exactly at the center of this plume. The simulations show that this modification has no influence on the temperature at the hot well, located at a distance of $1.7 \mathrm{~km}$ from the center of this cold plume. The influence at the cold well appears clearly during the first cycles, before declining and becoming negligible from the $8^{\text {th }}$ cycle on (Fig. 4).

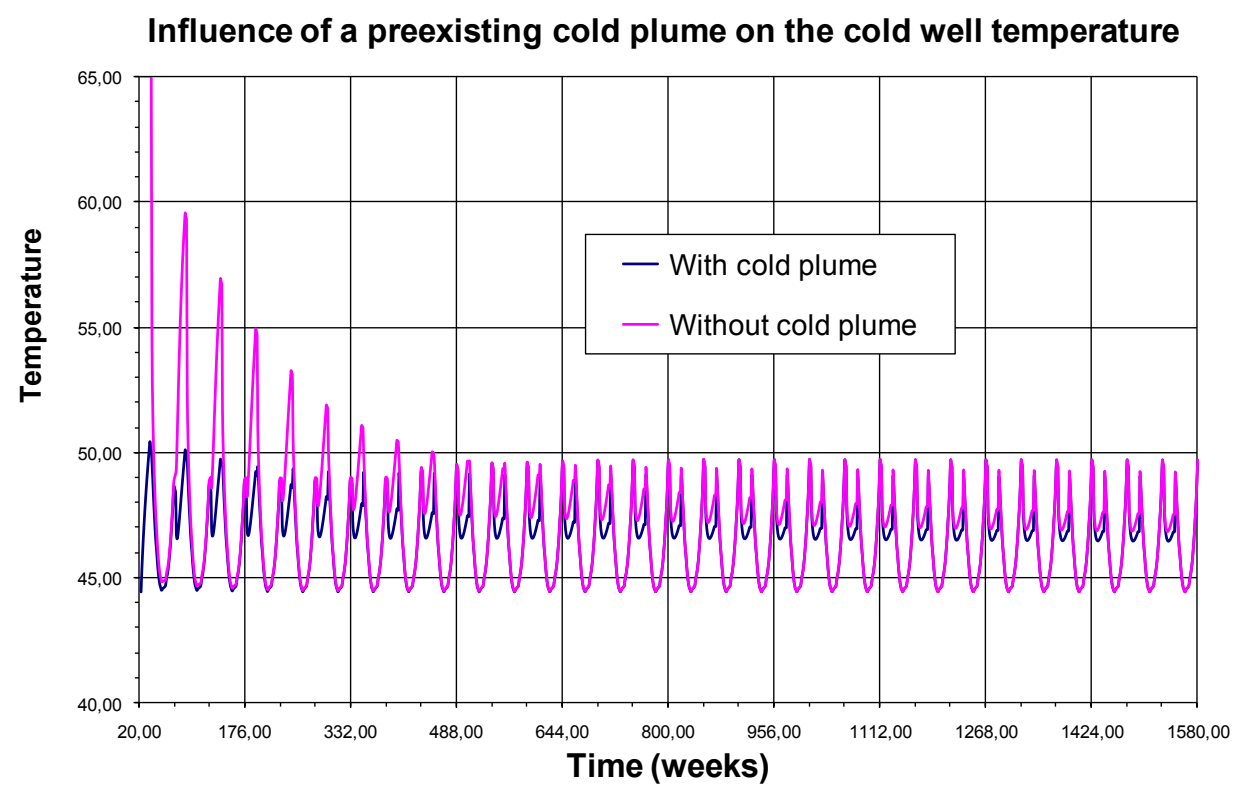

Fig. 4: Temperature at the cold well when positioning it on an existing cold plume (alternative case) compared to the reference situation. 


\subsubsection{Hot and cold plumes evolution in the reservoir}

Fig. 5 shows the distribution of "hot" and "cold" plumes in the reservoir after 5, 10 and 30 reference case ATES cycles (i.e. initial uniform temperature of $65^{\circ} \mathrm{C}$ ). Since the quantity of water exploited at the hot well is twice the quantity of water injected, on average $1380 \mathrm{kton}$ against 705 kton per cycle, the temperature distributions do not evolve similarly. Over successive contractions and expansions, the cold plume grows in the direction of the hot well over the cycles, similarly to the development around the injector well in a conventional geothermal doublet. The cold plume, defined as the region where the temperature decrease exceeds $1^{\circ} \mathrm{C}$, does not reach the hot production well or even the hot plume during the 30 years of ATES operation (see Fig. 5).

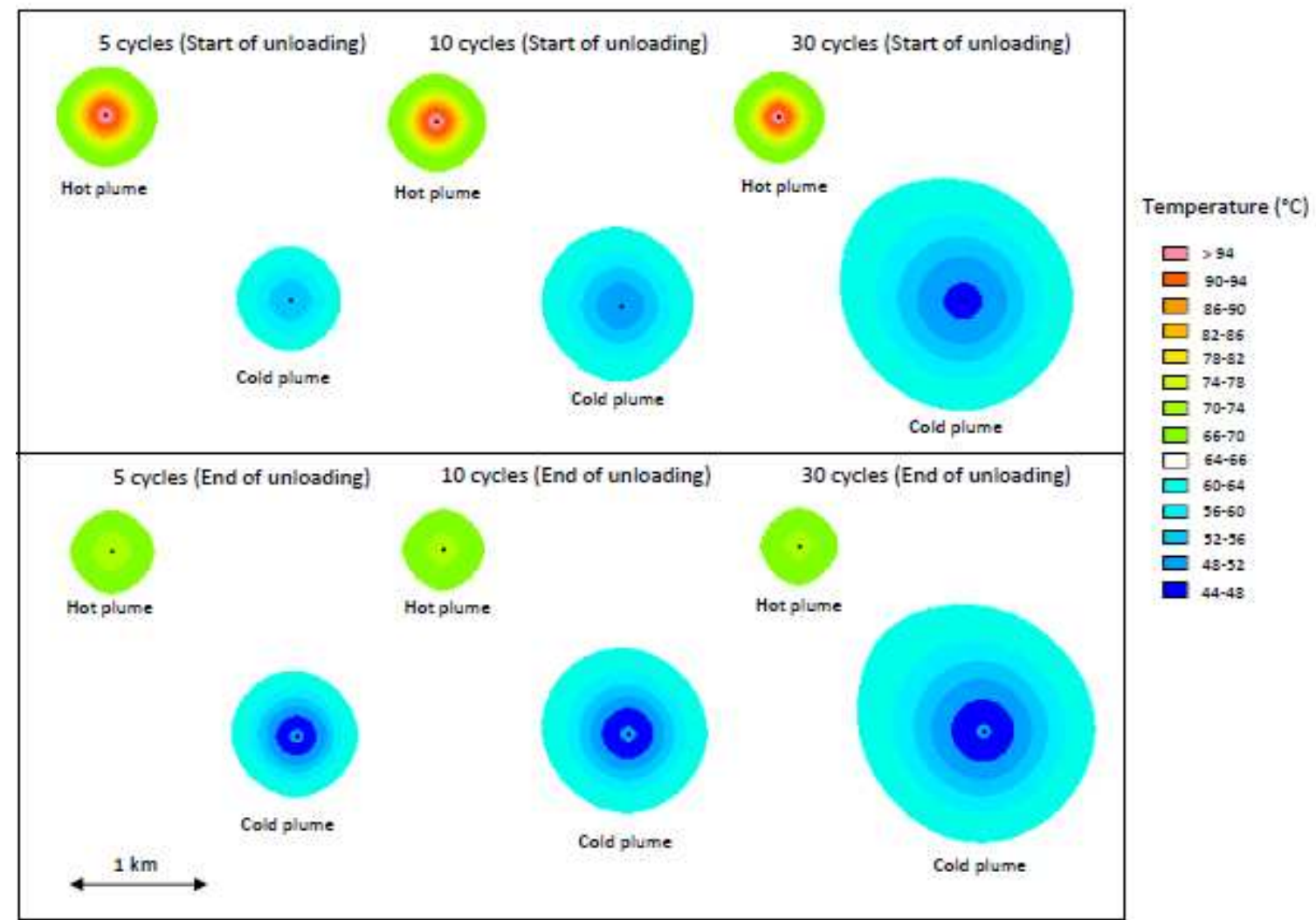

Fig. 5: Distribution of "hot" and "cold" water bodies after 5, 10 and 30 storage and unloading cycles.

Fig. 6 presents the reservoir temperature between the hot and cold wells during the $1^{\text {st }}, 5^{\text {th }}$, $10^{\text {th }}$ and $30^{\text {th }}$ cycles. It provides two types of information: the extent of the hot and cold plumes during ATES cycles and the heat stored during the summer and exploited in the winter. Moreover, the heat stored during a summer period is proportional to the temperature increase in the hot plume during that period. The difference in temperature profiles in the reservoir between the beginning and the end of a heat storage cycle (vertically hatched area) therefore represents the heat stored in the hot plume and the heat extracted in the cold plume. In addition, the difference between the original reservoir temperature $\left(65^{\circ} \mathrm{C}\right)$ and the temperature profile at the end of the $n$ th-cycle (slanting hatched area) represents the un-retrieved heat that may be considered as permanently stored at the hot well and the total heat extracted from the ground at the cold well, from the beginning of the 
operation to the $n$th cycle. At the end of the 30th cycle, the heat extracted from the aquifer by cooling it at the cold well is much higher than the heat lost by warming it at the hot well, which shows the overall extraction of energy from the reservoir, similarly to conventional geothermal energy.

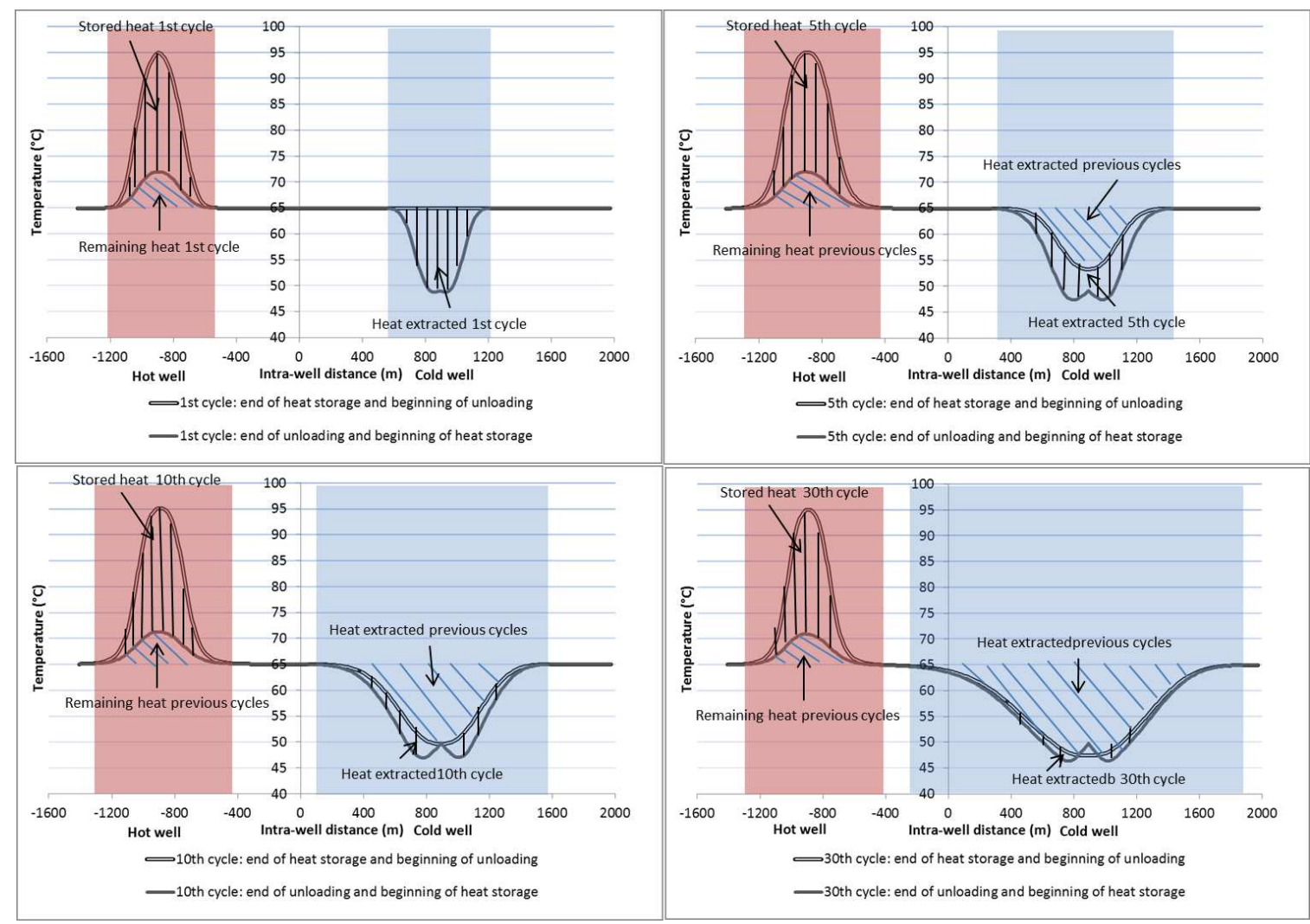

Fig. 6: Temperature at the hot and cold wells against intra-well distance for the $1^{\text {st }}$, $5^{\text {th }}, 10^{\text {th }}$ and $30^{\text {th }}$ cycles. The footprints of the hot (resp. cold) plume are outlined in red (resp. blue). The heat extracted from the aquifer during a cycle (resp. since the start of the ATES) is proportional to the cold plume temperature decrease over this cycle (resp. from the initial reservoir temperature), represented by the vertical hashing on the graph. Similarly, the stored energy during a cycle (resp. since the start of the ATES) is proportional to the temperature increase of the hot plume during that cycle (resp. since the start of the ATES).

\section{Calculation of the network energy mix}

An Excel application has been developed to calculate the network's energy mix over time, using maximum geothermal power and non-geothermal available energy as a complement when necessary. The application calculates the temperature of the available geothermal resource depending on the number of past cycles and on the mass of brine already unloaded during that cycle. This is then combined with the time-dependent load flow rate and "inlet" \& "outlet" temperatures in order to deduce the energy mix of the network over weeks and cycles. The architecture of the energetic model is illustrated in Fig. 7. The "heat exchanger" brown boxes at the center of the Fig. chain the different input components: operation, engineering constraints, load characteristics and geothermal resource. 


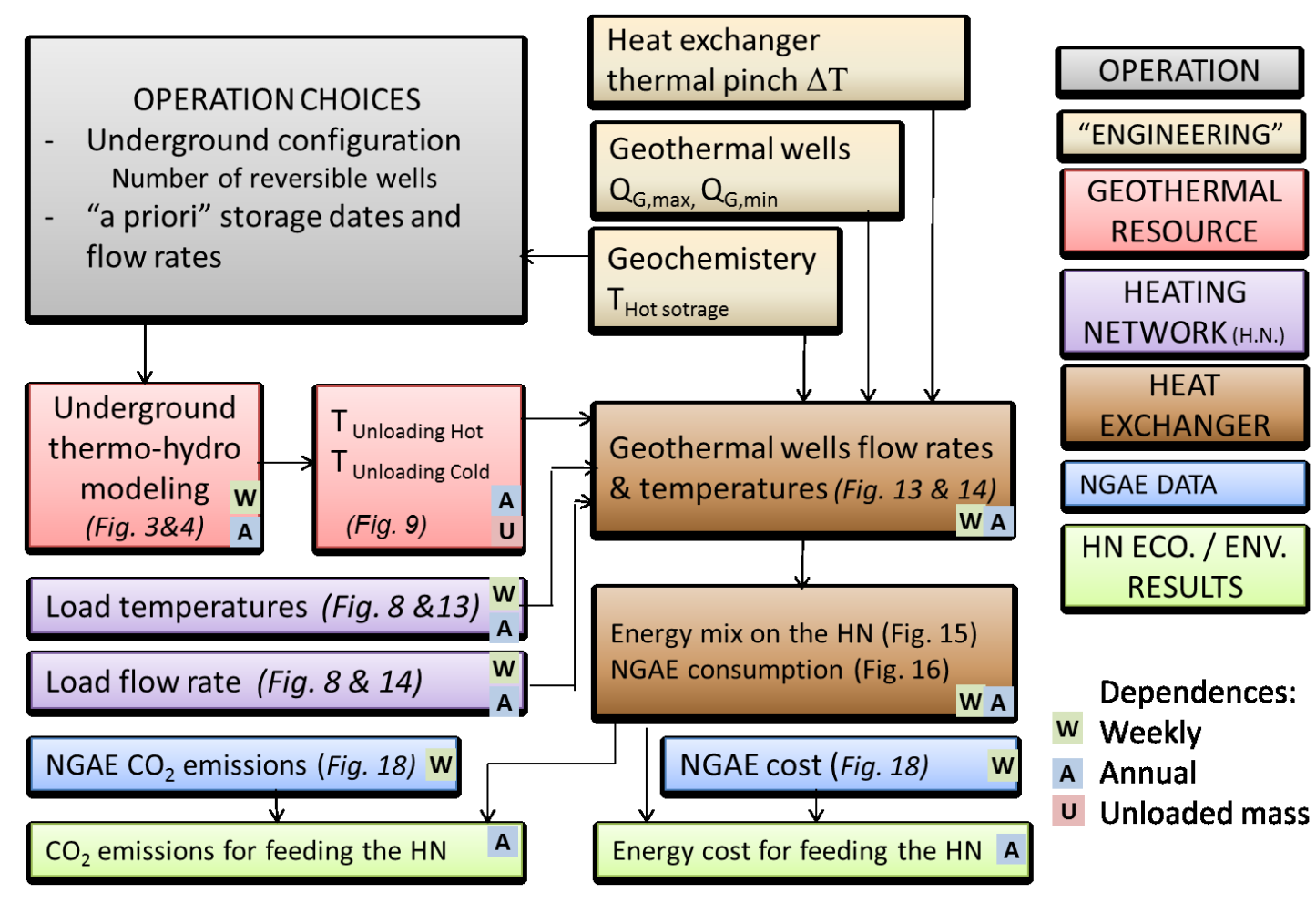

Fig. 7: Principle of the software for estimating the power delivered to the heating network. $H N$ stands for Heating Network and NGAE stands for Non-Geothermal Available Energy.

\subsection{Model inputs and constraints}

\subsubsection{District heating demand}

Below, we consider a large district heating network development in the lle de France region designed to deliver heat and hot water to 7,500 housing-equivalents. Since the average consumption in the region is $11.4 \mathrm{MWh}$ per year per housing-equivalent (Via-Sèva and Ademe, 2010), we estimate that the heating network delivers $85,000 \mathrm{MWh}$ per year, or $10 \mathrm{MW}$ on average. Network development is progressive starting at $40 \%$ of its final power in the first year and with linear growth to $75 \%$ by the fifth year and full development in the fifteenth.

The seasonal variation of the demand is chosen to be representative of Paris weather conditions according to conventional guidelines (Skagestad and Mildenstein, 2002) and to some observed networks in the Paris area. The power demand is weekly averaged, eliminating consumption peaks during less than a week. This assumption constitutes an adequate approach to address the seasonal demand variation which is well captured with a weekly time-step.

The water flow rate and temperature variations, presented in Fig. 8 for the final district demand, are representative of new designs currently envisaged for deployment of geothermal energy in the Paris basin. They are characterized by a low water return temperature in order to increase the thermal exchanges with the geothermal fluid (Snoek et al., 2002). 


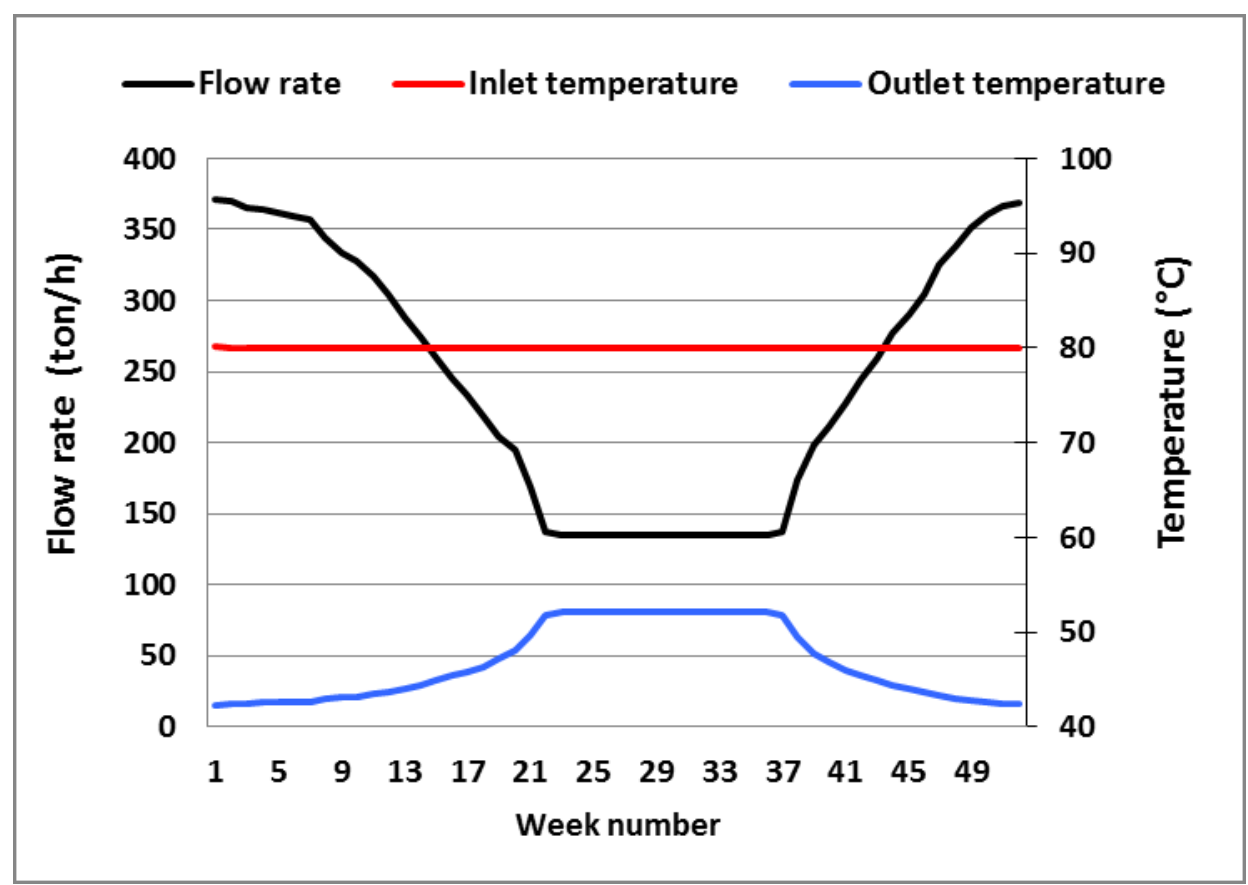

Fig. 8: Evolution of the heating network characteristics for the final district demand (cycles 15 to 30 )

\subsubsection{Operating assumptions}

We consider a geothermal system consisting of one doublet of reversible wells, as presented in the introduction. The model can be adapted to more complex ATES configurations, such as two parallel reversible doublets, synchronized or not.

The simulation forecasts 30 years of operation, the typical duration assumed for geothermal energy projects. The starting dates for storage and pauses and durations can vary. Based on the load time-variation (Fig. 8), we consider hot storage dates from week 23 to week 36 and hot unloading from week 39 to week 21 of the following year. These periods are separated by 2 week pauses.

\subsubsection{Geothermal resource}

Unlike conventional geothermal energy plants, the temperatures of the geothermal resource

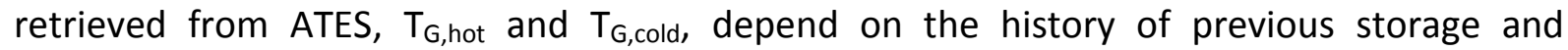
unloading. Notably, at a given time $t_{0}, T_{G, \text { hot }}\left(t_{0}\right)$ depends on the history of the ATES flow rate $\mathrm{Q}_{\mathrm{G}}\left(\mathrm{t}<\mathrm{t}_{0}\right)$. Moreover, the unloading flow rate $\mathrm{Q}_{\mathrm{G}}\left(\mathrm{t}_{0}\right)$ is itself depending on the resource temperature $T_{G \text {,hot }}\left(t_{0}\right)$ during the winter season since it is set in order to deliver maximum geothermal power to the heating network.

Numerical simulations presented in Section 2 have assessed the geothermal temperatures against time $T_{G \text {,hot }}(t)$ and $T_{G \text {,cold }}(t)$ (Fig.s 3 and 4) for a given baseline operation scenario with pre-defined variation in flow rate over time $\mathrm{Q}_{\mathrm{G}}(\mathrm{t})$. To overcome this interdependence between the geothermal temperatures $T_{G \text {,hot }}$ and $T_{G \text {,cold }}$ and the flow rate $Q_{G}$, these results are converted into brine temperature on the basis of the unloaded mass of brine for each cycle (Fig. 9).

Expressed in this manner, the temperature of the available resource is then used to calculate the network energy mix and the geothermal flow rates over time, which can be slightly 
different from the modeled baseline operation scenario without requiring new numerical simulations. We also note that, as long as the hot and cold water bodies are not interacting, the distance between these two wells in the aquifer is not important from a thermal point of view and the model can represent different kinds of underground geometric configurations (intra-well distance, number of reversible doublets).

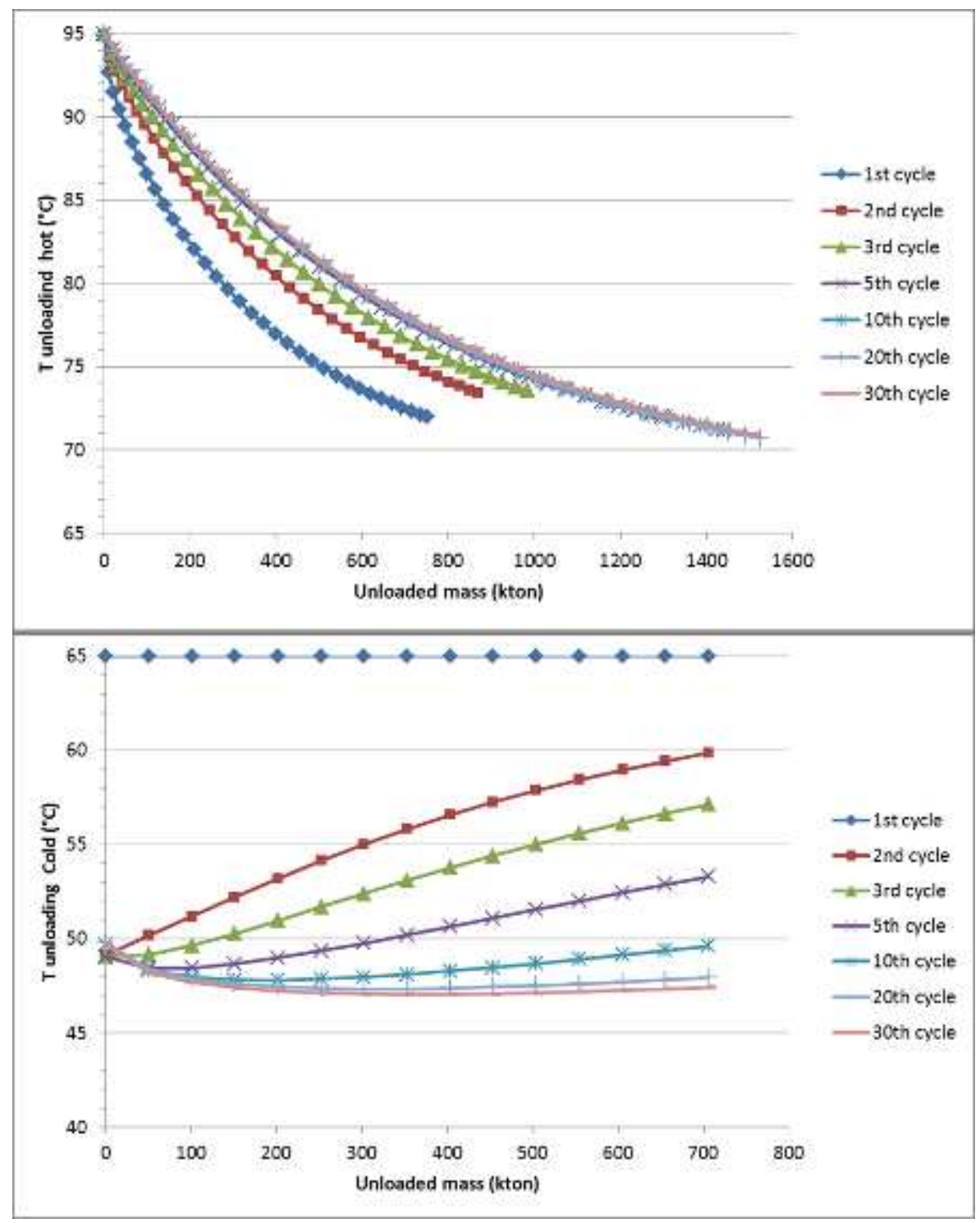

Fig. 9: Changes in temperature at hot and cold wells against the unloaded mass of brine over several cycles

Fig. 9 enables comparison of the evolution of the retrieved brine temperature over cycles. At the hot well, retrieved temperature (Fig. 9, top panel) decreases from the storage temperature of $95^{\circ} \mathrm{C}$ down to $71-74^{\circ} \mathrm{C}$ over successive cycles. Even though the duration of hot unloading was set constant at 34 weeks (Section 2), the mass of unloaded hot brine increases over the first five cycles in order to deliver more power in accordance with district heating network expansion.

During the first cycle, the temperature at the cold well (Fig. 9, bottom panel) is the original aquifer temperature, $65^{\circ} \mathrm{C}$. From the $2^{\text {nd }}$ cycle on, cold unloading begins at $49^{\circ} \mathrm{C}$, which corresponds to the temperature of cold brine injection at the end of the previous winter. 
The temperature at the cold well then increases with the extraction of cold water. From the fifth cycle on, the cold well temperature decreases first due to the heating network outlet temperature variations during the winter (Fig. 8). This temperature is used to set the cold water injection temperature, which therefore varies from $50^{\circ} \mathrm{C}$ at the beginning of cold injection, down to $44^{\circ} \mathrm{C}$ during the coldest weeks and then back to $49^{\circ} \mathrm{C}$ at the end of the heating season.

Fig. 9 also shows that the temperature at the end of unloading decreases during the 30 cycles at the cold well, whereas it is stable at $71^{\circ} \mathrm{C}$ from the $5^{\text {th }}$ cycle on at the hot well. This is a consequence of the almost stable hot plume from the $5^{\text {th }}$ cycle on and of the constantly growing cold plume, as presented in Fig. 6.

\subsubsection{Engineering constraints}

The achievable flow rate for the geothermal wells and the possible storage temperature limit the power of the ATES directly. These parameters are constrained by engineering designs and reservoir integrity respectively.

The geothermal well flow rate limit is set at $Q_{G \max }=300 \mathrm{~m}^{3} / \mathrm{h}$, representative of the rates achieved by geothermal doublets that have recently come into operation in the same Dogger aquifer (Lopez et al., 2010). A minimum flow rate of $Q_{G \min }=150 \mathrm{~m}^{3} / \mathrm{h}$ is assumed to be acceptable for the submersible electric pumps of the productive wells.

The rapid temperature change in the geothermal water modifies the equilibrium between dissolved and solid minerals, and can therefore induce dissolution or precipitation, the latter being likely to cause decreases in porosity and permeability, or dissolution. Cold injection is not constrained, since it is similar to the cold injection by currently operating geothermal doublets. Conversely, there is no similar industrial experience of warming of the Dogger brine and the geochemical impact has therefore been assessed through numerical simulations of reactive transport, as presented in Castillo \& Azaroual (2010). For the purposes of this article, a storage temperature $T_{G \text { storage }}=95^{\circ} \mathrm{C}$ is considered.

In addition, the thermal energy exchanges between the geothermal brine and the heating network water are also limited by the heat exchanger. A thermal pinch $\Delta T=2^{\circ} \mathrm{C}$ is considered.

\subsection{Heat exchanger model}

In this paragraph we refer to the notations presented in Table 2. Temperatures are expressed in ${ }^{\circ} \mathrm{C}$, flow rate in $\mathrm{m}^{3} \cdot \mathrm{h}^{-1}$ and power in $\mathrm{MW}$. We also define the constant $\mathrm{C}=4.18$ $\mathrm{MJ} \cdot \mathrm{m}^{-3} \cdot \mathrm{K}^{-1}$. 


\begin{tabular}{ll}
\hline Notation & Symbol \\
\hline Temperature at the hot well & $\mathrm{T}_{\mathrm{G} \text { hot }}$ \\
Temperature at the cold well & $\mathrm{T}_{\mathrm{G} \text { cold }}$ \\
Hot storage temperature & $\mathrm{T}_{\mathrm{G} \text { storage }}$ \\
Geothermal flow rate during the winter & $\mathrm{Q}_{\mathrm{G}}$ \\
Geothermal power feeding the network & $\mathrm{P}_{\mathrm{G}_{\rightarrow} \mathrm{HN}}$ \\
Geothermal flow rate during the summer & $\mathrm{Q}_{\mathrm{G}, \text { storage }}$ \\
Power used for hot water storage & $\mathrm{P}_{\mathrm{NGAE} \rightarrow \mathrm{G}}$ \\
Heating Network flow rate & $\mathrm{Q}_{\mathrm{HN}}$ \\
Heating Network inlet temperature & $\mathrm{T}_{\mathrm{HN} \text { in }}$ \\
Heating Network outlet temperature & $\mathrm{T}_{\mathrm{HN} \text { out }}$ \\
NGAE power feeding the network & $\mathrm{P}_{\mathrm{NGAE} \rightarrow \mathrm{HN}}$ \\
Thermal pinch & $\Delta \mathrm{T}$ \\
\hline
\end{tabular}

Table 2: Notations used in the model (NGAE stands for Non-Geothermal Available Energy)

During the summer storage season (Fig. 10), non-geothermal available energy sources are used both for storage and for feeding of the heating network. We assume that the wells are used at their maximum flow rate. The power used for storage is given by:

$$
\mathrm{P}_{\mathrm{NGAE}->\mathrm{G}}(\mathrm{t})=C \cdot Q_{\mathrm{G}, \text { storage }}\left(T_{\mathrm{G}, \text { storage }}-T_{\mathrm{G}, \text { cold }}(t)\right)
$$

The power used to feed the network during the summer is given deduced from the network temperatures and flow rate:

$$
\mathrm{P}_{\mathrm{NGAE}->\mathrm{HN}}(\mathrm{t})=\mathrm{P}_{\mathrm{HN}}(\mathrm{t})=C \cdot Q_{\mathrm{HN}}(t)\left(T_{\mathrm{HN} \text { in }}(t)-T_{\mathrm{HN} \text { out }}(t)\right)
$$

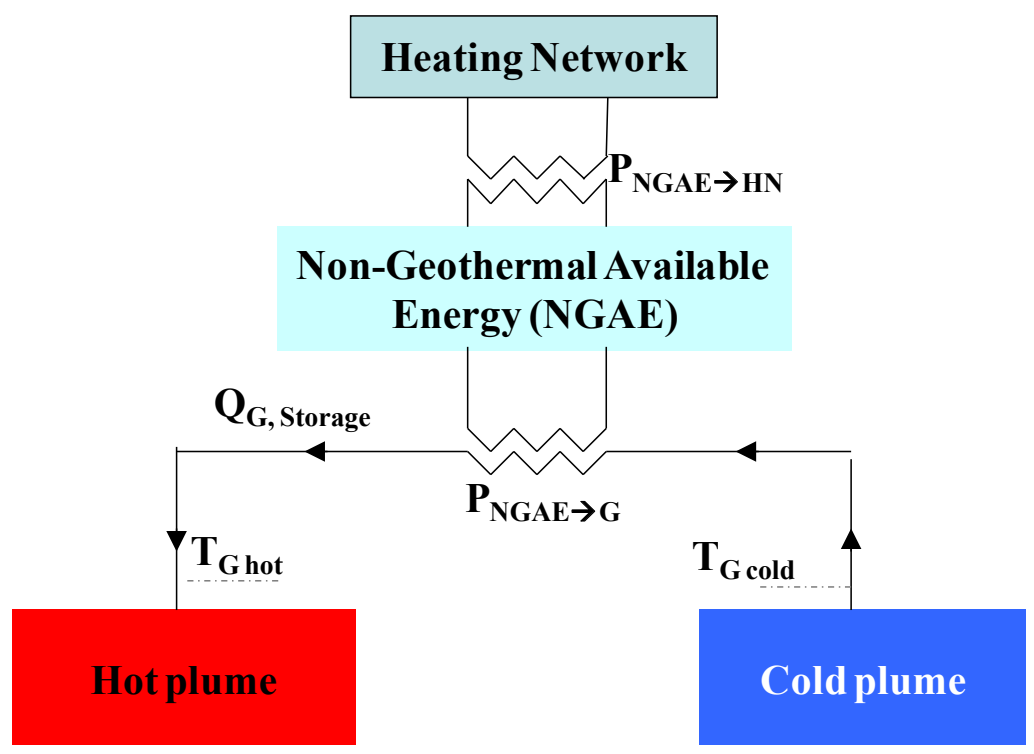

Fig. 10: During the summer, the unloaded cold brine is heated using non-geothermal available energy sources and stored in the aquifer. It is injected into the hot well at a maximum rate and at the highest temperature allowed by engineering and geochemical constraints. 
During the winter unloading period (Fig. 11), the heating network is fed by both the geothermal system and other available energy sources. The geothermal power delivered to the heating network is given by:

$$
\mathrm{P}_{\mathrm{G}-\mathrm{HN}}(\mathrm{t})=C \cdot Q_{\mathrm{G}}(t)\left(T_{\mathrm{G}, \text { hot }}(t)-T_{\mathrm{G}, \text { cold }}(t)\right)
$$

In order to extract maximum energy from the geothermal resource, the cold injection is set as low as possible: $\mathrm{T}_{\mathrm{G} \text { cold }}(\mathrm{t})=\mathrm{T}_{\mathrm{HN} \text { out }}(t)+\Delta T$. The hot unloading temperature $\mathrm{T}_{\mathrm{G} \text { hot }}$ is given by the simulations as presented in Section 3.2.

For calculation of the instantaneous geothermal flow rate $Q_{G}$, four cases are distinguished based on the well maximum rate constraint $Q_{G}<Q_{G}$, max and on the fact that non-geothermal available energy sources are required if the geothermal resource is not hot enough to warm the heating network water to network inlet temperature. As illustrated in Fig. 12, this leads to four cases for determination of the geothermal flow rate $Q_{G}$.

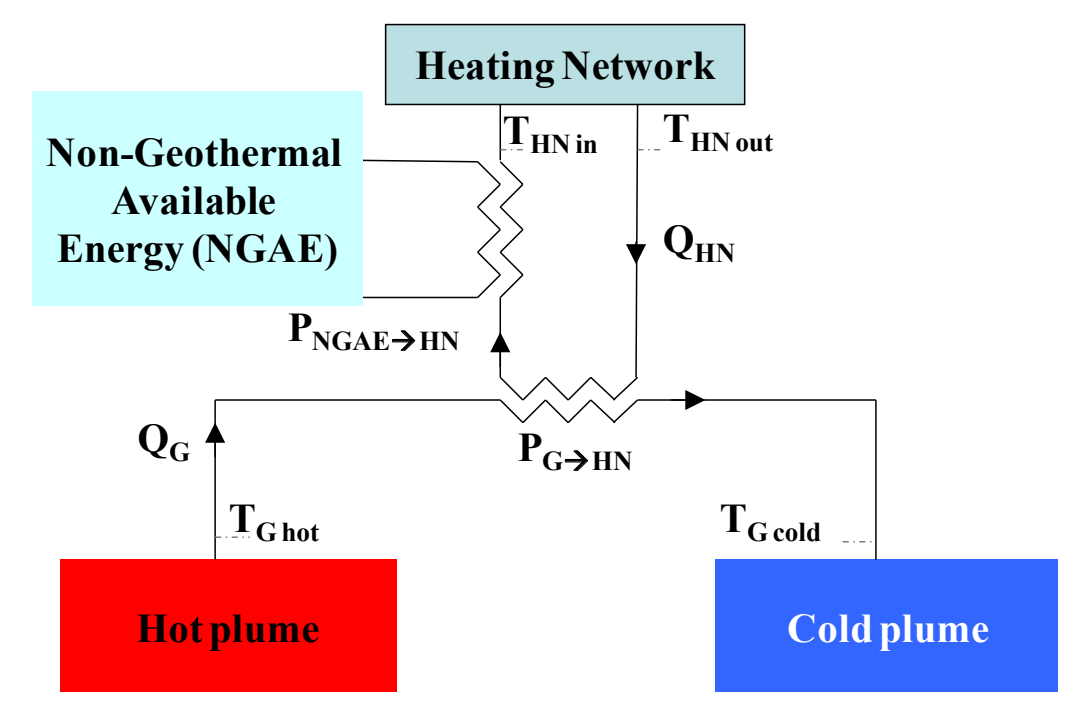

Fig. 11: During the winter, the unloaded hot brine and possibly other non-geothermal available energy sources are used to feed the heating network. Cold brine is injected at time-varying temperature and flow rate, based on the heating network outlet temperature and on the thermal exchanges conditions 


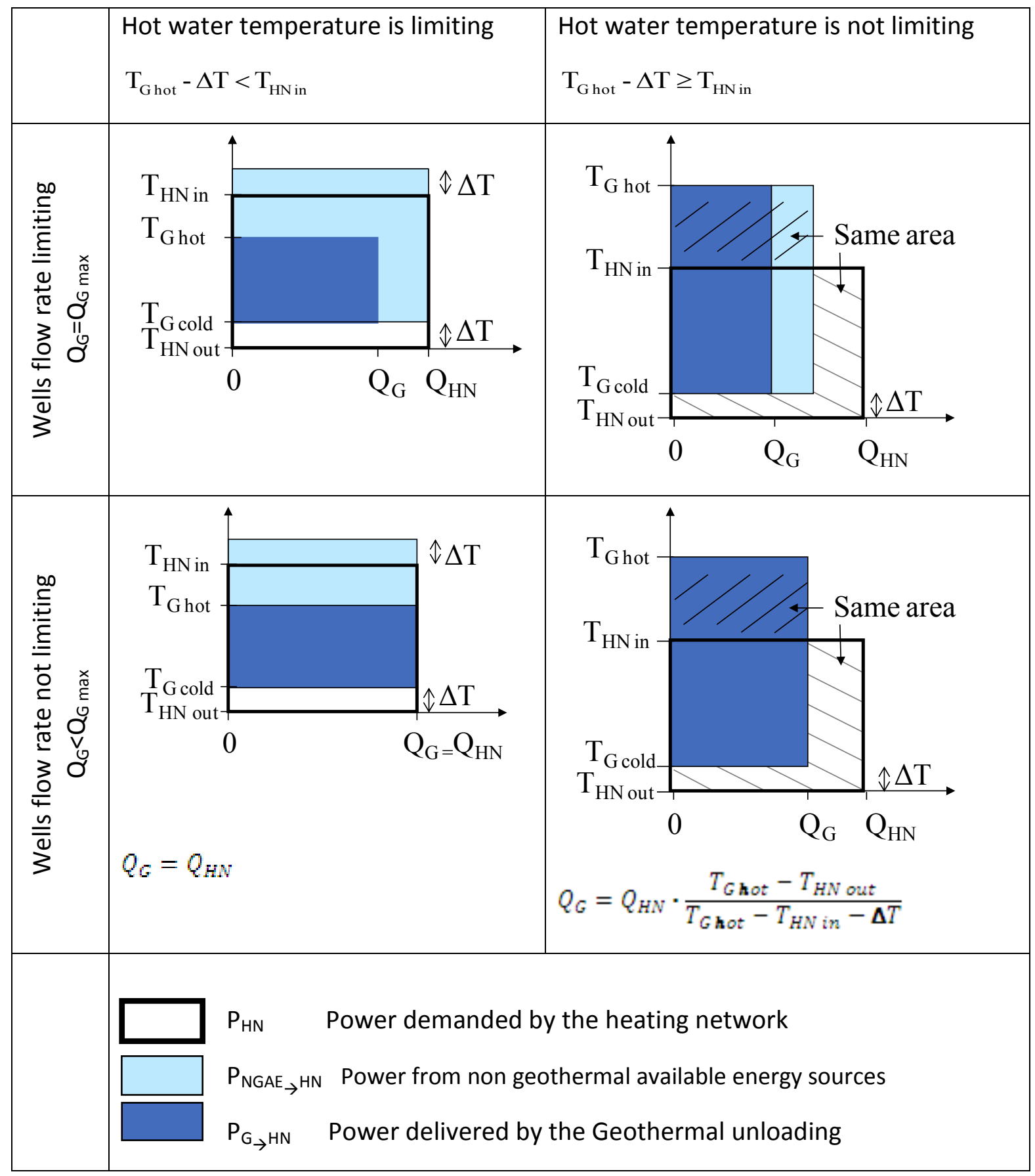

Fig. 12: Use of geothermal and non geothermal available energy energy sources to feed the heating network during the winter, depending on temperature and flow rate limitations. When the geothermal temperature $T_{G, \text { hot }}$ cannot warm the heating network water to the inlet temperature, non-geothermal available energies are used (left column). In addition, the geothermal well flow rate cannot exceed $Q_{G, \max }$ which can also limit the possible geothermal power delivered to the network (top row). The combination of these two constraints results in four cases, for each of which the geothermal flow rate $Q_{G}$ is expressed. 
The heating network demand $\mathrm{P}_{\mathrm{HN}}$ is therefore met by a maximum of geothermal energy, other energy sources being used in addition, if necessary:

$$
\mathrm{P}_{\mathrm{NGAE}->\mathrm{HN}}(\mathrm{t})=\mathrm{P}_{\mathrm{HN}}(\mathrm{t})-\mathrm{P}_{\mathrm{G}->\mathrm{HN}}(\mathrm{t})=C \cdot Q_{\mathrm{HN}-}(t)\left(T_{\mathrm{HN} \text { in }}(t)-T_{\mathrm{HN} \text { out }}(t)\right)-\mathrm{P}_{\mathrm{G}->\mathrm{HN}}(\mathrm{t})
$$

\section{Energy results}

\subsection{Energy mix of the heating network}

The previous section has presented the energy model and its input parameters. This section presents the results, which are based on temperature and flow rate fluctuations, as presented in the Fig.s 13 and 14 for the first, fifth and last $\left(30^{\text {th }}\right)$ storage and unloading cycle of this case study. During the last, $30^{\text {th }}$, seasonal cycle, the four conditions illustrated in Fig. 12 are met successively, showing that considering the fluctuation of the temperatures and flow rates is necessary for correct evaluation of the power that can be unloaded from an ATES to a heating network:

- From week 39 to week 45 of the $30^{\text {th }}$ cycle, neither flow rate nor temperature are limiting and network demand is met fully by geothermal unloading.

- From week 46 to 49 , only well flow rates are limiting.

- From week 50 to week 12 , both temperature and wells are limiting.

- From week 12 to week 20 (end of unloading), only temperature is limiting.

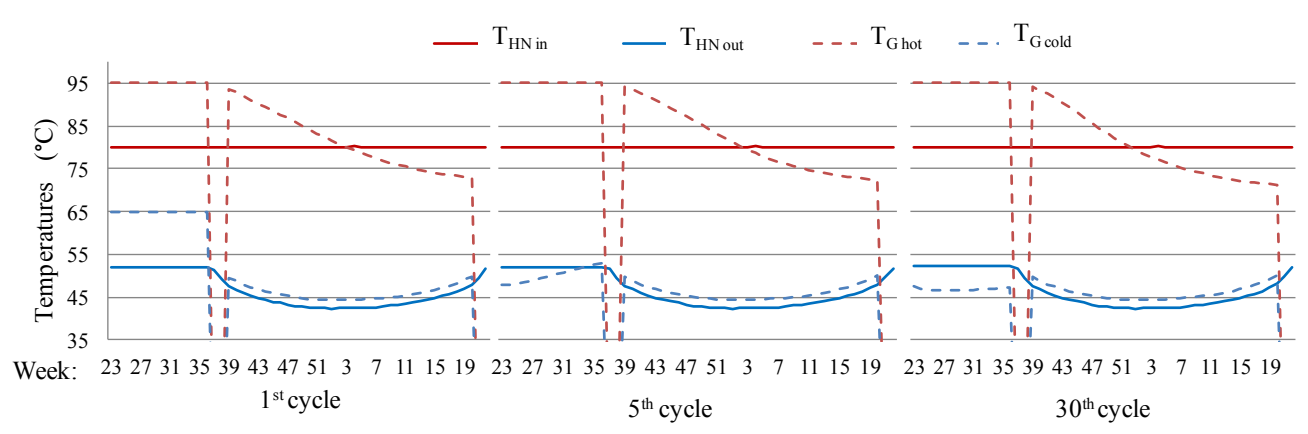

Fig. 13: Temperatures at the geothermal hot and cold well (resp. $T_{G \text { hot }}$ and $T_{G \text { cold }}$ ) and at the inlet and outlet of the heating network (resp. $T_{H N}$ in and $T_{H N \text { out }}$ ) during the $1^{\text {st }}, 5^{\text {th }}$ and $30^{\text {th }}$ cycle 


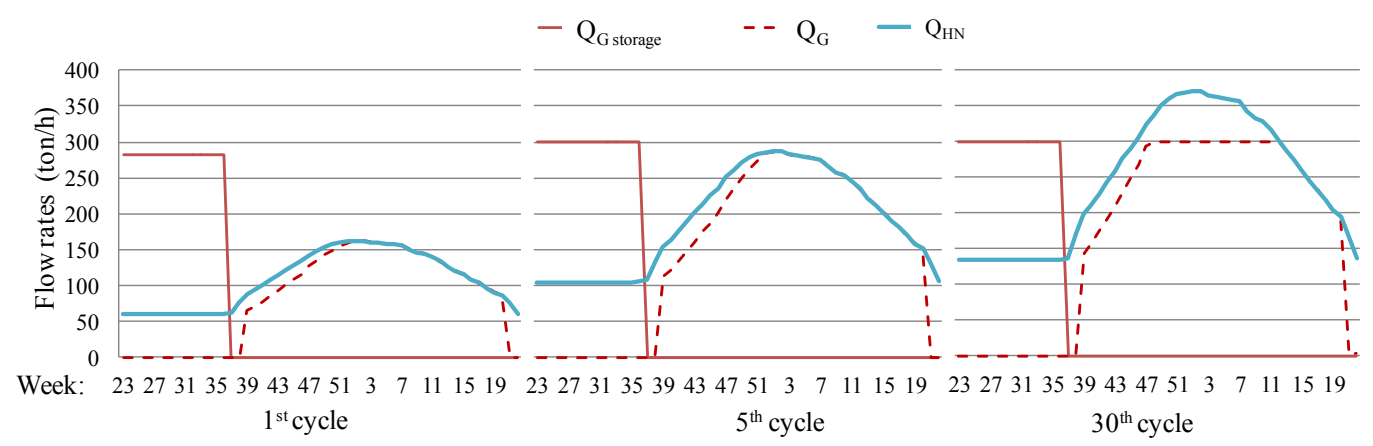

Fig. 14: Flow rates through the heating network $\left(Q_{H N}\right)$ and through the geothermal wells during the summer storage and the winter unloading (resp. $Q_{G \text { storage }}$ and $Q_{G}$ ) for the $1^{\text {st }}, 5^{\text {th }}$ and $30^{\text {th }}$ cycle.

Based on these results, the energy mix of the heating network can be evaluated on a weekly basis during the 30 years of operation. Geothermal unloading can meet the demand fully during the first half of unloading. During the second half, the geothermal temperature is not high enough and additional energy sources are used to reach the network inlet temperature (Fig. 15).

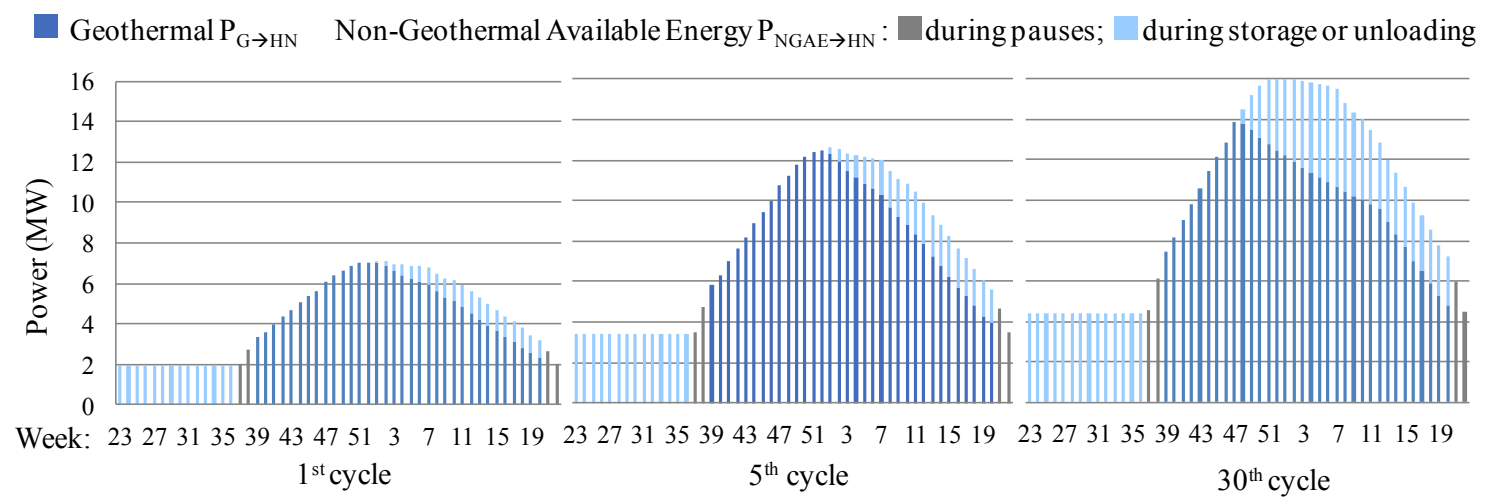

Fig. 15: Energy mix of the district heating network during the $1^{\text {st }}, 5^{\text {th }}$ and $30^{\text {th }}$ cycles

During the first cycle, the ATES provides $29 \mathrm{GWh}$ to the heating network, i.e. $75 \%$ of a 39 GWh demand. During the $5^{\text {th }}$ cycle, the higher temperature of the unloaded brine enables the ATES to deliver more energy to the heating system and the ATES to maintain its share in the energy mix: it represents $76 \%$ of the $67 \mathrm{GWh}$ demand. Once the network demand is mature, from the $15^{\text {th }}$ cycle on, the ATES share in the energy mix is stable at $67 \%$ of the 86 GWh annual demand.

In average over the 30 years of operation, the ATES delivers $54 \mathrm{GWh}$ /year to the heating system, i.e. a power of $9.5 \mathrm{MW}$ during the 34 unloading winter weeks, and represents a $70 \%$ share of the energy mix.

In comparison, a conventional geothermal doublet without seasonal energy storage used for powering the same heating network would deliver in average of $36 \mathrm{GWh} /$ year during the 30 years, representing a $50 \%$ share of the energy mix. 


\subsection{Non-geothermal available energy consumption over time}

Non-geothermal available energy sources are used both directly on the network as a supplementary energy source to geothermal power, and to warm the geothermal brine to its storage temperature during the summer, as presented in Fig. 16.

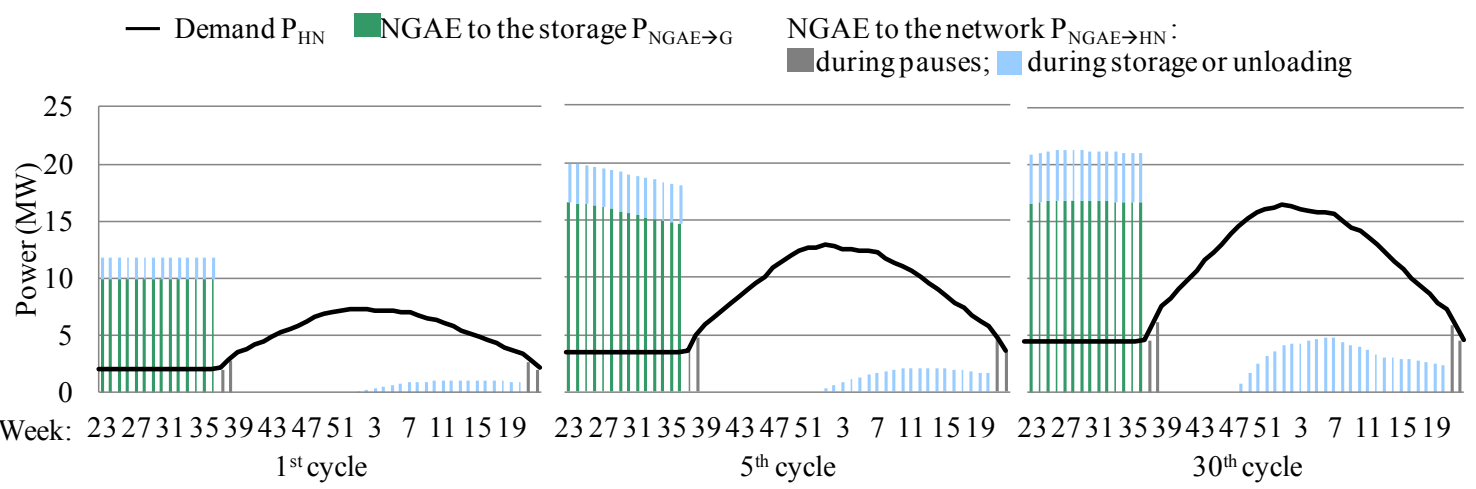

Fig. 16: Demand profile and non-geothermal available energy (written NGAE in the Fig.) consumption for storage and direct use on the network during the $1^{\text {st }}, 5^{\text {th }}$ and $30^{\text {th }}$ cycles

During the summer period, Non-geothermal available energy use for hot storage is proportional to the storage flow rate and to the temperature increase when warming the geothermal brine. Since storage is at constant flow rate and temperature, the variation patterns of the cold brine temperature (Fig. 9, bottom panel) directly explain the fluctuations over weeks and cycles observed in power consumption for the storage $P_{\mathrm{NGAE}_{\rightarrow} \mathrm{G}}$ (Fig. 16, green bars). For instance, we note that initial storage requires much less energy than subsequently, since the cold brine was produced at the initial reservoir temperature, whereas it is colder in the following cycles after the creation of the cold plume.

During the $1^{\text {st }}$ cycle, $23 \mathrm{GWh}$ are used for hot storage, $36 \mathrm{GWh}$ during the $5^{\text {th }}$ one and 40 GWh during the last $30^{\text {th }}$ cycle. In average over the 30 years of operation, $38 \mathrm{GWh}$ per year are used for heating the brine for the summer hot storage, i.e. a power of $16 \mathrm{MW}$ during the 14 weeks of summer storage.

\subsection{Storage efficiency}

Fig. 17 presents the ratio of the geothermal energy used to feed the network divided by the energy expended for storage. This definition is close to that of storage efficiency, but it should be borne in mind that our example is not a pure storage solution but a mix of storage combined with a conventional use of the geothermal energy: it may therefore exceed 1. Both the reference case (cold well initially at $65^{\circ} \mathrm{C}$ ) and the alternative case (cold well located on a cold plume left by a former geothermal exploitation) are considered. Fig. 17 shows that efficiency increases steadily through the cycles and tends to stabilize close to $150 \%$ at 10 years. The only exception to this trend is the high value observed during the first reference cycle for the reference $65^{\circ} \mathrm{C}$ case, since the brine was produced at $65^{\circ} \mathrm{C}$ during initial storage, which is much higher than the cold temperature production during the following cycles (explanation provided in Section 3.2) 


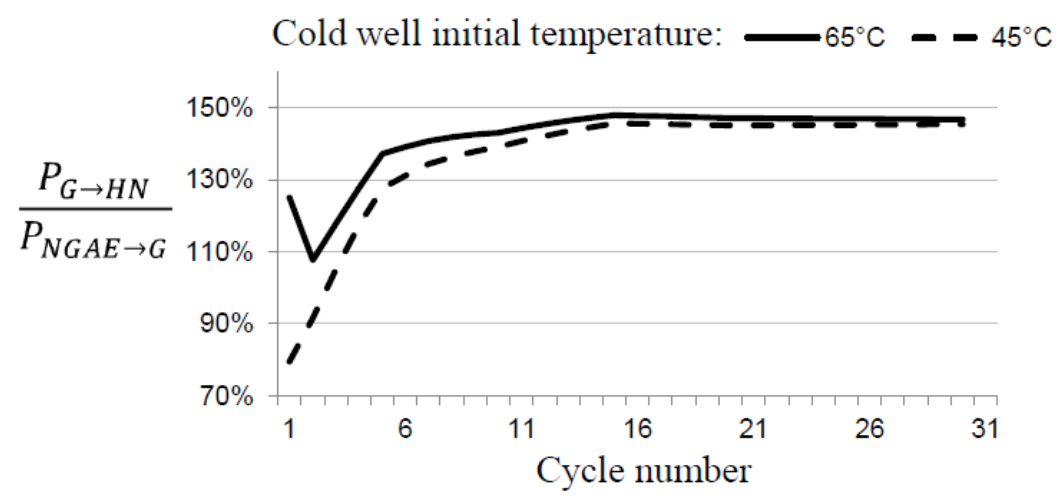

Fig. 17: Evolution of storage efficiency, i.e. the ratio of the geothermal energy feeding the network to the energy used for storage. In the reference case, both wells were initially located in the aquifer at $65^{\circ} \mathrm{C}$. In the alternative case, the cold well is located on an existing cold plume at $45^{\circ} \mathrm{C}$.

Over the 30 years of operation, the average value of this efficiency ratio is $143 \%$ for the reference case, and $137 \%$ for the alternative case, since the lower cold brine temperature induces an increase in energy consumption during the first summer hot storages. This example shows that the impact on storage efficiency of locating the cold well at the location of a former cold plume is marginal.

\section{Conclusion}

This work shows that ATES should consider the aquifer and the heating network as a single system in order to make proper energy analyses. Numerical simulations of the geothermal hot and cold storage and unloading cycles in the Dogger aquifer have been coupled with a realistic 7500 households-equivalents district heating network power demand in order to estimate the network's energy mix and the geothermal energy use over time. Results show that the ATES would provide $54 \mathrm{GWh}$ per year to the heating system, geothermal energy providing $70 \%$ of the energy mix. It is significantly higher than the $50 \%$ share which is possible with a conventional geothermal doublet. Moreover, since ATES avoids the consumption of expensive and high carbon-emissions energies during the winter retrieval while consuming relatively cheap surplus low-carbon energy during the summer storage, it can be part of the technical solution to be implemented for fulfilling France's national objective of increasing by $50 \%$ the heat produced by renewable energies before 2050 .

In addition, the thermal simulations suggest that placing the cold storage on the location of an existing cold plume only has a limited influence on the overall thermal efficiency of the ATES (reduction from $143 \%$ to $137 \%$ ), which is particularly interesting for the Paris region: ATES plants would enable geothermal energy development to be pursued in areas that, due to the cold resource temperature, are not, or are no longer, of interest for low-enthalpy geothermal doublets. 


\section{Acknowledgments}

Thanks are due to the two unnamed reviewers for constructive criticism and helpful suggestions. This work was supported by the ANR (French National Research Agency) under the STOCK-E 2007 program.

\section{References}

Andersson, O., 2007. Aquifer thermal energy storage, in: Paksoy, H.O. (Ed.), Thermal Energy Storage for Sustainable Energy Consumption. Springer, Dordrecht, The Netherlands, 2007; pp. 155-176.

Ademe, 2009. Energie et climat - Chiffres clés 2009. Ademe Editions ed. Ref. 6607, 86 pp. (in French).

Bourbiaux, B., 2011. ATES Contribution to the Housing Energy Balance: a Simple Assessment Methodology. Oil \& Gas Science and Technology-Revue d'IFP Energies nouvelles, 66(1), 2136.

Castillo, C., Azaroual, M., 2010. Reactive Transport Simulations of Geochemical Processes Induced by the ATES Operations in the Dogger Aquifer (Paris Basin), in XXXVIII IAH Congress 12-17/09/2010 - Krakow - Poland.

Cordier,E., Goblet, P., 1998. Programme METIS. Simulation d'écoulement et de transport miscible en milieu poreux et fracturé. Notice d'emploi au 9/7/98 - Rapport ClG-École des Mines $C I G / L H M / R D / 98-37$. (in French)

Cordier,E., Goblet, P., 2009. Projet GEOSTOCAL. Analyse de l'influence de la structure du réservoir géothermique sur son évolution thermique. Report R100515PGOB. (in French)

Cordier,E., Goblet, P., 2010. Projet GEOSTOCAL. Simulations de l'évolution thermique du réservoir. Report R101217ECOR. (in French)

Hamm V., 2011. Modélisation des impacts hydrauliques et thermiques sur l'aquifère du Dogger pour un stockage de chaleur intersaisonnier. Report BRGM/RP-59647-FR. (in French)

Kabus F., Hoffmann F., Mollmann G., 2005. Aquifer Storage of Waste Heat Arising from a Gas and Steam Cogeneration Plant - Concept and First Operating Experience, Proceedings from the World Geothermal Congress 2005, Antalya, Turkey, pp. 24-29.

Kabus F., Wolfgramm M., Seibt A., Richlak U., Beuster H., 2009. Aquifer Thermal Energy Storage in Neubrandenburg - Monitoring Throughout Three Years of Regular Operation, Proceedings of the $11^{\text {th }}$ international Conference on thermal energy storages -Effstock 2009-, June 14-17 2009, Stockholm, Sweden.

Kabus, F., Möllmann, G., Hoffmann, F., Bartels, J., 2006. Two-year Experience in the Operation of an Aquifer Thermal Energy Store Based on Surplus Heat Arising from a Gas and Steam Cogeneration Plant at Neubrandenburg, NE Germany. Proceedings of the $10^{\text {th }}$ International Conference on Thermal Energy Storage (EcoStock), Pomona, New Jersey.

Lee, K. S., 2010. A review on Concepts, Application, and Models of Aquifer Thermal Energy.Storage Systems. Energies 3(6), 1320-1334. 
Lopez, S., Hamm, V., Le Brun, M., Schaper, L., Boissier, F., Cotiche, C., Giuglaris, E., 2010. 40 years of Dogger Aquifer Management in Ile-de-France, Paris Basin, France. Geothermics 39(4), 339-356

Nielsen, K., 2003. Thermal energy storage: a state-of-the-art. A Report within the Research Program "Smart Energy-Efficient Buildings at NTNU and SINTEF", 2003.

Sanner, B., 1999. High Temperature Underground Thermal Energy Storage; State-of-the-Art and Prospects. IEA ECES Annex 12 - report, 1999. Giessener Geologische Schriften No. 67

Snoek, C., Yang, L., Onno, T., Frederiksen, S., Korsman, H., 2002. Optimisation of a District Heating System by Maximizing Building heating System Temperatures Differences, IEADistrict Heating and Cooling report S2.

Skagestad, B., Mildenstein, P., 2002. District Heating and Cooling Connection Handbook, IEADistrict Heating and Cooling, Annex VI

Thiéry, D., 1990. MARTHE Software. Modeling of Aquifers with a Rectangular Grid in Transient State for Hydrodynamic Calculations of Heads and Flows. Release 4.3.BRGM report 4S/EAU no.R32548.

Ungerer, Philippe, Le Bel, Laurent., 2006. Le stockage de chaleur en aquifère : une nouvelle perspective pour la géothermie. Revue des ingénieurs des Mines 423, Sept./Oct. 2006, p.4446. (in French)

Via Sèva, Ademe, 2010. Annuaire 2010 des réseaux de chaleur et de froid Région par région. Report 6864, May 2010, 243pp. (in French)

\section{Internet resources}

SYTCOM website, "environment protection " webpage consulted on May 4th, 2011. (French) http://www.syctom-paris.fr/edi/reduction-nuisances-dechets/effetserre.html 